\title{
Students' Writing Difficulties in English for Business Classes in Dhofar University, Oman
}

\author{
Sani Yantandu $\mathrm{Uba}^{1} \&$ Nizar Mohammed Souidi ${ }^{1}$ \\ ${ }^{1}$ Department of English Language \& Literature, Dhofar University, Salalah, Oman \\ Correspondence: Sani Yantandu Uba, Department of English Language \& Literature, Dhofar University, Salalah, \\ Oman.
}

Received: January 28, 2020

Accepted: March 4, 2020

Online Published: March 9, 2020

doi:10.5430/ijhe.v9n3p86

URL: https://doi.org/10.5430/ijhe.v9n3p86

\begin{abstract}
This study investigates students' writing difficulties of English for business classes and the possible factors that might cause such difficulties. A corpus of forty essays of forty undergraduates was compiled. We adopted a textography approach to study writing practices. The results of the textual analysis informed an administration of questionnaire to both the students and four faculty members. The results of the corpus analysis indicate that students had a lot of errors in spelling, grammar, and many of them were unable to write thesis statement, as well as topic sentences. Some students also had problems in developing coherent essays. The contextual data suggests that about 90 per cent of the respondent did not know what thesis statement is. It also shows that the majority of students had problems in generating and organising ideas and nineteen out of twenty-one respondents also had a limited wide range of vocabulary. The course syllable did not allocate more than four hours for teaching essay writing throughout the semester. We strongly recommend more contact hours for teaching essay writing. Teachers could engage students in critical thinking activities, including how to generate and organise ideas. Teachers should be teaching more academic vocabulary to students.
\end{abstract}

Keywords: essay writing, English for business, writing difficulties, textography

\section{Introduction}

Many scholars argue that writing is a complicated cognitive task (Al-Khairy, 2013). Al Fadda (2012:124) also claims that academic writing is 'a mental and cognitive activity since it is a product of the mind'. Nunan (1989) also shares a similar view that writing is difficult involving cognitive activity requiring writers to take into account various factors. Alsamadani (2010) believes that the complexity and difficulty of academic writing arise from the fact that writers must find a thesis statement, writing supporting details, 'organizing, revising, and finally editing it to ensure an effective, error-free piece of writing' (p.53). A text 'must be cohesive, logical, clearly structured, interesting and properly organized with a wide range of vocabulary and mastery of conventions in mechanics (Fareed, et al., 2016: 81). In addition, learners must conform to the genre, conventions, disciplines and institutional practices within which they are writing. Another complexity arises when writing in a second language (Hyland, 2003).

\subsection{Reviews of Previous Studies}

Many research studies have been conducted on essay writing in contexts of English as a Second Language (ESL), focusing on one or more aspects of writing elements. Al-Khasawneh, \& Maher (2010) examined writing of Arab postgraduates of the college of business in one of the Malaysian universities. They found that students faced difficulty in many elements of writing such as a lack of wide range of vocabulary, organization of ideas, spelling and grammar errors. Ahmed (2010) focused his study on ELF learners' cohesion and coherence in essay writing in Egypt. He adopted a mixed method approach. The findings indicated that students faced difficulties in writing up thesis statement, topic sentences, generating ideas and sequencing of ideas. One of the possible reasons was that the students did not have background knowledge of specific topics. The second reason was low English proficiency of the students made it difficult to develop coherent writing. In another study, Javid, Farooq, \& Gulzar, (2012) explored perceptions of English-major undergraduates', as well as their teachers regarding English language teaching. The findings identified that students' English proficiency is poor when admitted on the course.

Al-Khairy (2013) investigated undergraduates' academic writing difficulties in one of the Saudi Arabian universities. The study showed that there are recurring errors in their academic writings. One of the most frequent errors was inappropriate use of vocabulary. Spelling error was also frequent in the students' corpus. The study strongly 
recommended that more English language courses should be incorporated on the programme in order to strengthen students writing skills. In another study, Javid \& Umer (2014) revealed some of the writing problems that Saudi EFL learners are facing. One of their findings indicated that the students frequently used inappropriate lexical items. They also had weaknesses in generating and organizing ideas, as well as using correct grammar. The study recommended more sessions for academic writing practice. Al Badi, (2015) investigated writing difficulties of ESL learners from four different nationalities in one of the Australian universities. The findings suggested that all the participants seem to have similar difficulties regardless of their different educational backgrounds. Some of the difficulties were related to cohesion and coherence. One of the possible factors for the difficulty was a lack of knowledge of disciplinary discourse, as well as a lack of knowledge of expectations of institutional writing practices. Fareed, et al. (2016) focused their study on ESL undergraduate learners' writing problems and possible factors in one of the universities in Pakistan. The study adopted a qualitative approach. The findings of the study showed that students had serious problems in relation to language proficiency, such as grammar, vocabulary and syntax. Other problems associated with their writings were lack of ideas, weak organizational structure and over reliance on mother tongue. Some of the possible factors which might influence the way they write were a lack of writing and reading practice, as well as a lack of generating ideas and low motivation. Ali (2017) focused his study on teachers' perceptions on pupils' writing difficulties. Alfaqiri (2018) also investigated writing difficulties and challenges of Saudi Arabian EFL learners. The findings indicated that students did not have experience in writing English, as well as experiencing difficulty in grammar.

The above studies focused on different contexts and elements of academic writing. However, none of the studies focused on Omani context, involving students of English for Business. In addition, the previous studies did not adopt a textography approach to study writing practices. Swales (2013) defines textography as a 'partial ethnography' involving a combination of textual analysis and exploring the contexts of writing. This study seeks to address the following research questions:

1. What writing errors are frequently recurring in students' essays?

2. What are the possible factors might cause such errors?

\section{The Context of the Study}

This study was conducted in Spring Semester of 2018-2019 in the Department of English Language and Literature, Dhofar University, Salalah, Oman. The course was ENGL 203B: English for Business. It was taught throughout the semester of about 17 weeks. One of the prerequisites for registering the course was student must pass ENGL 102B. It was a three credit hour course. The course syllable allocated a three-hour session for teaching the argumentative essay. The students who were enrolled on the course registered the course as one of the University requirements course. The students were from majors related to Commerce and Business Administration.

\section{Methodology}

This study adopted a textography approach to study students' writing practices. A corpus data of forty argumentative essays of forty students was developed. The students were asked to write a four-paragraph argumentative essay of about 350 words. The essays were accessed after the students had written their final examination. The rationale was to get more insight on what difficulties students are facing in essay writing. The essays were analyzed and categorized into various elements of writing. Some of the elements are presence of thesis statement, presence of four topic sentences, presence of cohesion and coherence, errors related to capitalization, spelling, article, grammar, subject-verb agreement, etc.

The results of textual analysis informed an administration of a mix of closed and open-ended questionnaire (see appendix I) to the forty students, although only 21 participants filled in the questionnaires and submitted to the researchers. An open-ended questionnaire (see appendix II) was administered to four faculty members who have been teaching the course. We also examined the course syllable to explore more insight about the expectations of the course in relation to essay writing, as well as sessions or contact hours allocated to teaching essay writing.

Regarding reliability of the questionnaires, we asked other faculty members to read and offer some feedback in order to ensure consistency of the questions. The coding of the responses was also asked a second coder to do his own coding in order to maintain consistency and accuracy.

In terms of validity, Dornye (2007) states that one of the ways to validate a research is 'contextualization and thick description'. We provided the context of our study and procedures in collecting the data, as well as analyzing and presenting the data. 
We used bar chart and table in presenting the result because readers could clearly see the findings and the differences. We also used a thematic analysis in analyzing the findings of open-ended questionnaires of both the students and teachers.

\section{Results}

As mentioned above, this study analyses students' essay and identifies what errors are frequently recurring and what are the possible causes of such errors. We will now present the results of both textual analysis and questionnaires.

\subsection{Textual Analysis}

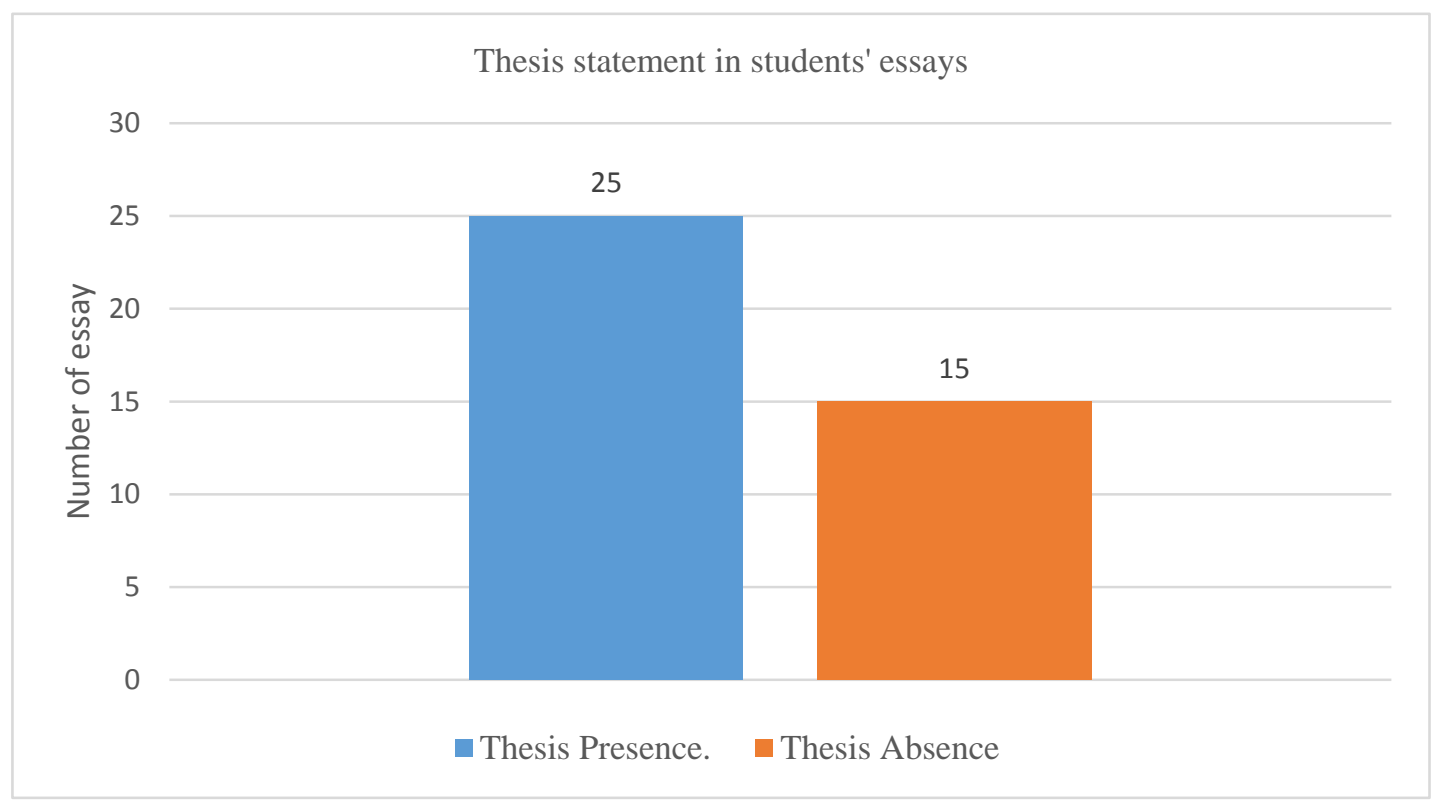

Figure 1. Presence of thesis statement

The Figure 1 shows that 25 out of 40 students did write thesis statement in their essay, whereas 15 students did not write any thesis statement. For example, one student writes:

Indeed, there are some advantages; however, there are also some disadvantages (Paper 12)

The writer shows that he/she takes up an objective stance, that he/she will discuss both advantages and disadvantages of spending your holidays away from your home country.

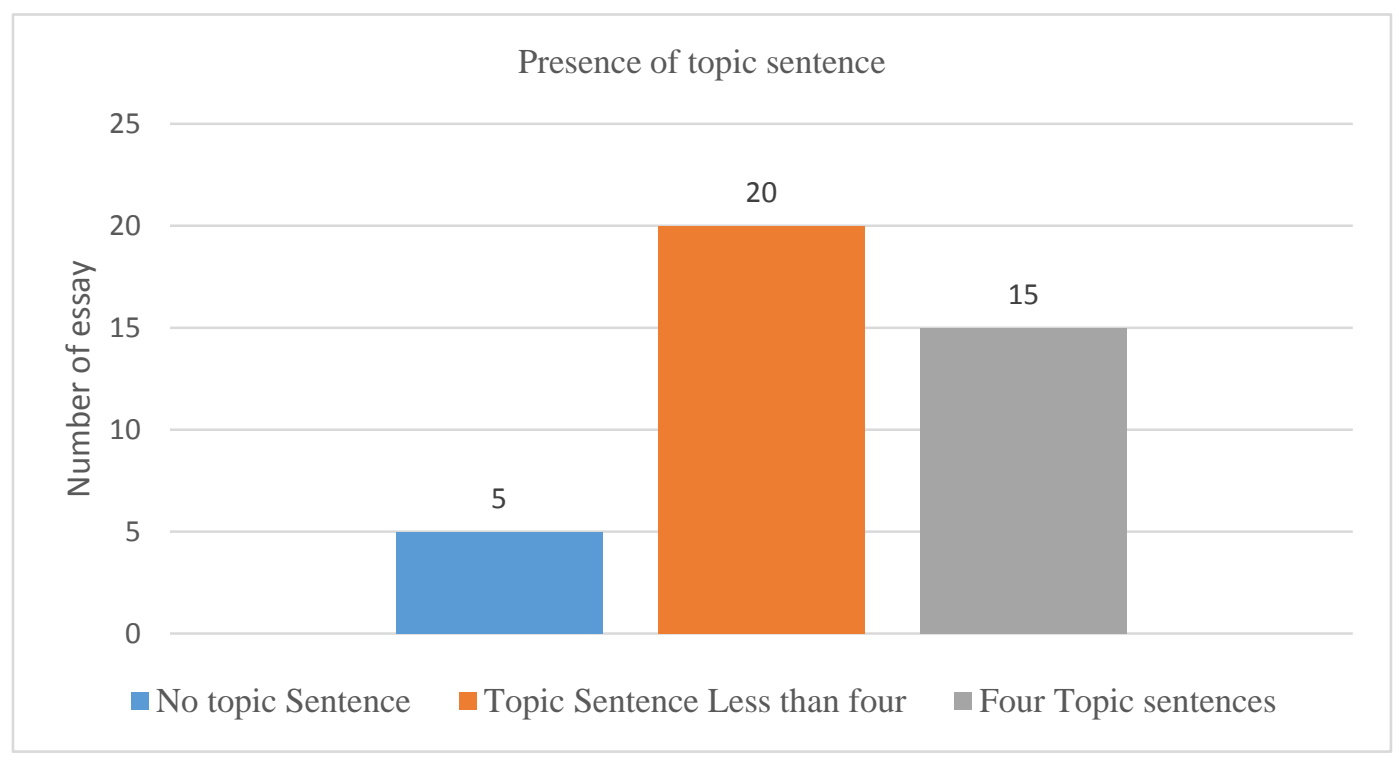

Figure 2. Presence of topic sentence 
The result in Figure 2 shows the presence or absence of topic sentence in the students' essays. As can be seen, 20 out of 40 students did not have four topic sentences in all the paragraphs. They typically had less than four topic sentences as required by the writing task. On the other hand, 15 students did meet the requirement of the writing task by having four topic sentences in the four paragraphs. However, 5 out of the 40 students did not write any topic sentence across the four paragraphs. This shows that 50 per cent of the students did not meet the requirements of the writing task by having at least four topic sentences.

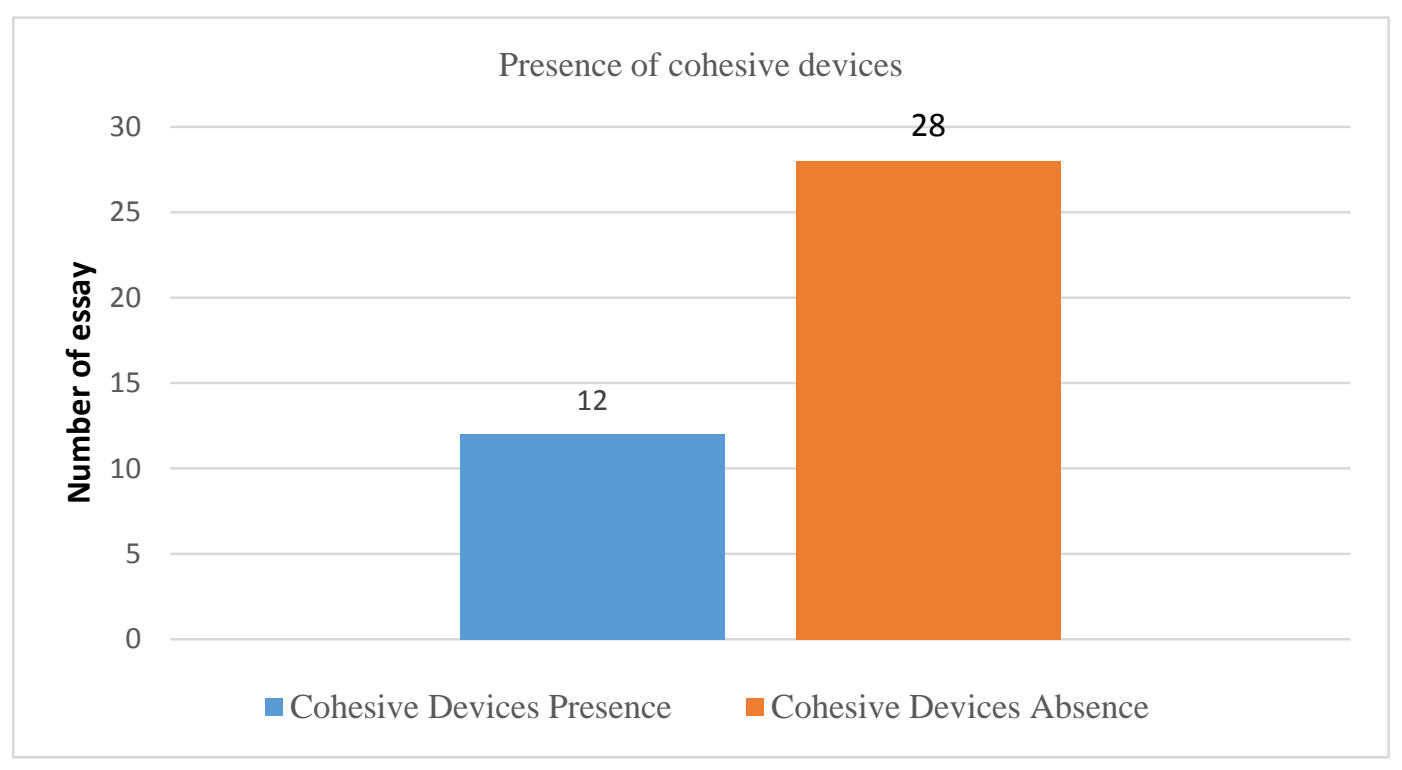

Figure 3. Presence of cohesive devices

The result in Figure 3 indicates to what extent the students used contrastive discourse markers. As can be seen only 12 out of 40 students did use some kind of contrastive cohesive devices. We expect that since the writing task is an argumentative essay the students might have used a lot of such devices in expressing contrastive views. One example in the student's essay is:

On the other hand, there is disadvantage from spending vacation away from your home country the tickets sometimes are very expensive. (Paper 1)

The writer begins the second body paragraph with a contrastive cohesive device because in the preceding body paragraph one he/she discusses some of the advantages of spending a vacation in another country.

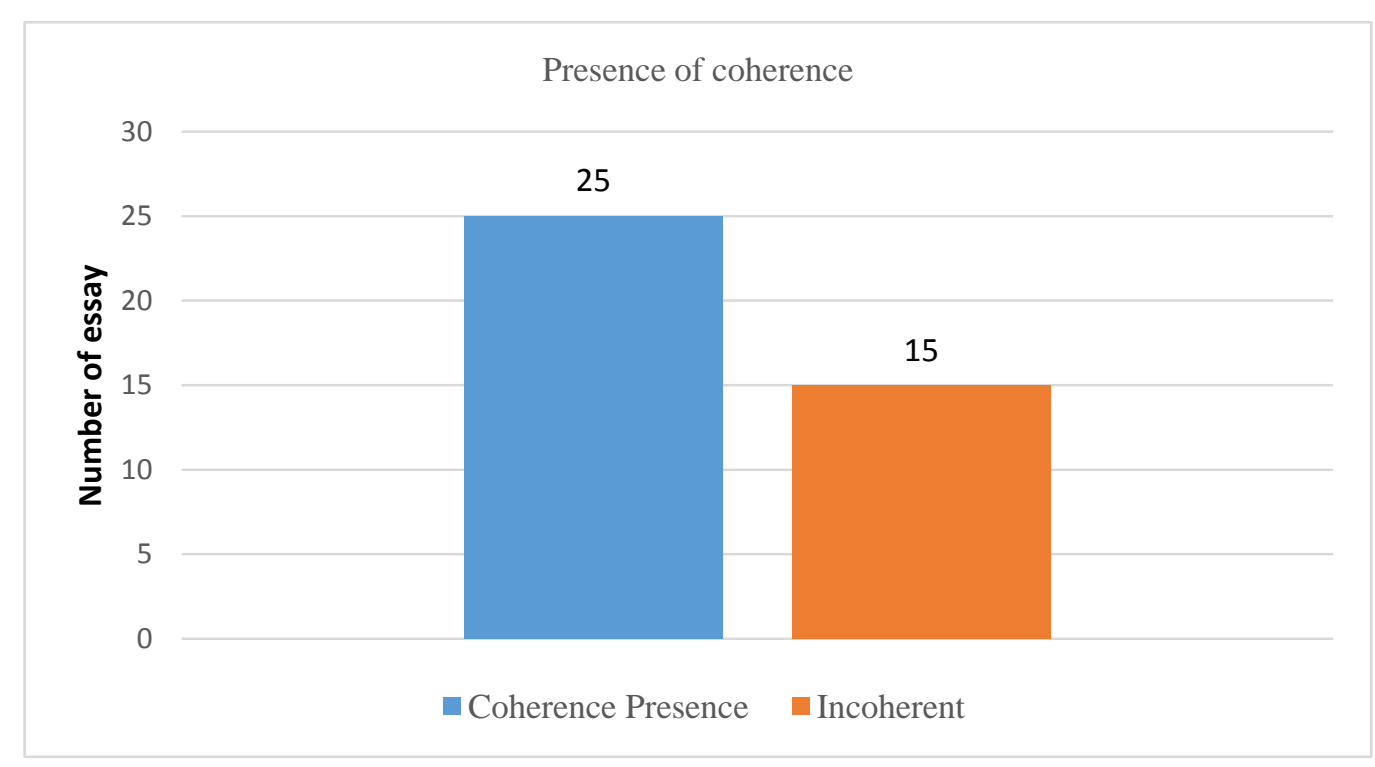

Figure 4. Presence of coherence 
The result in Figure 4 shows whether each essay is having some kind of coherence or not. As can be seen 25 out of 40 essays are coherent. This suggests that they organized their ideas in a logical manner. However, 14 essays did not have coherence which made it difficult for the reader to fully comprehend their line of thoughts. One example from incoherent essay is:

The advantages and disadvantages about only topics the advantages and disadvantages of investing money in hotel salalah business in margting kebing business that buy and sell securities unable to pay debts or continue to do business in salalah of the which kind of bonds affect the because (paper 27)

This clearly shows a lack of coherence in the paper because the writer was not focused on the topic of the essay; but rather he/she mixes up the topic with another topic which the writing task does not require. As can be seen in the excerpt the writer does not punctuate which makes it a little bit incoherent.

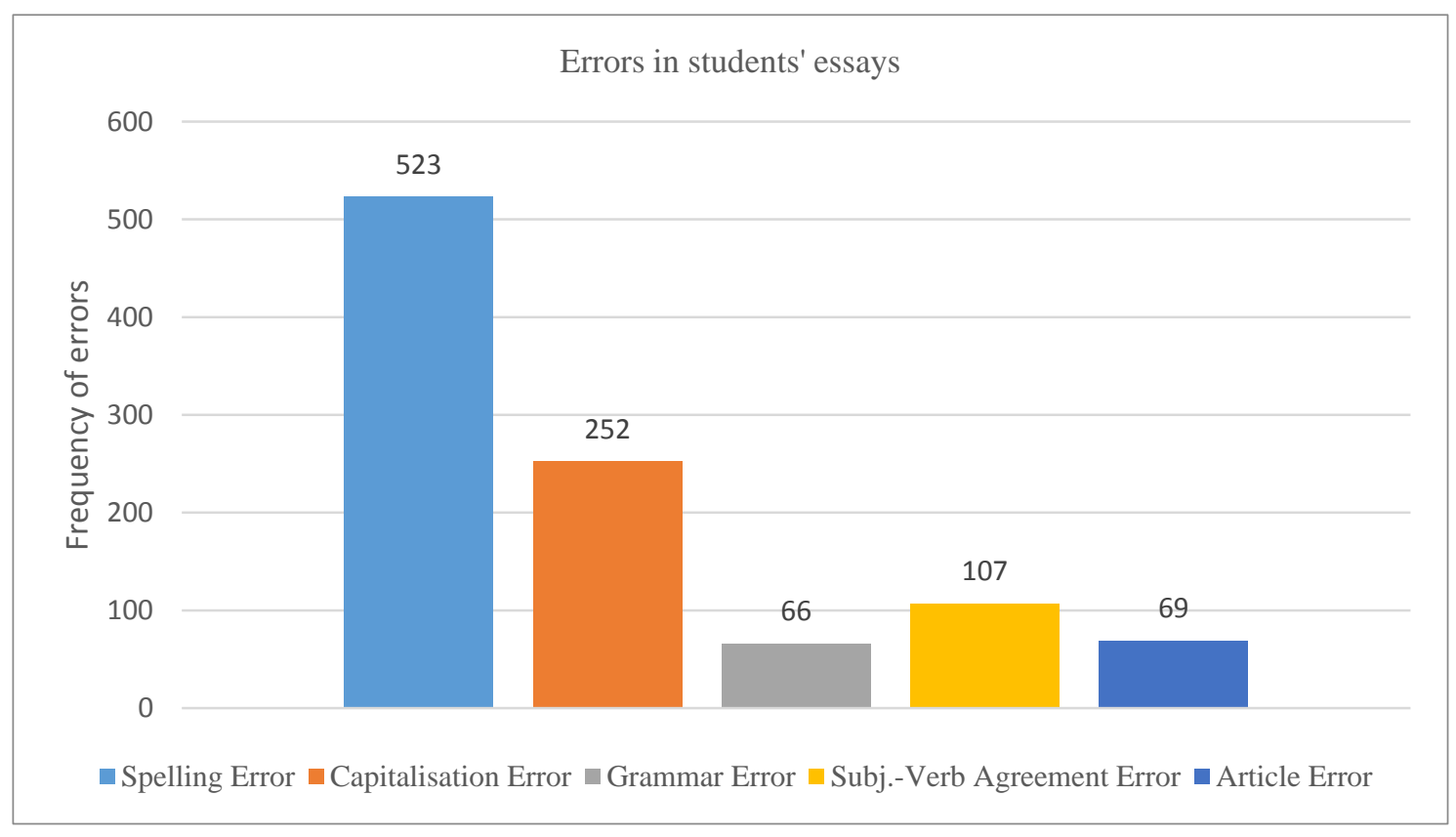

Figure 5. Errors in students' essays

The Figure 5 is a result of comparative analysis of different kind of writing errors which are typically occurred in the students' corpus. As can be seen we compared five elements: spelling, capitalization, grammar, subject verb agreement and article errors. The most recurring error in the students' corpus is the spelling error. The spelling error had a total frequency of 523 occurrences in the corpus. In fact, all the forty essays had a spelling error but with varying degree of frequencies, with the highest had thirty-four occurrences and lowest had three occurrences. Some examples in the corpus are:

\section{Mony instead of money}

Becous instead of because

Wither instead of weather

Resouns instead of reasons

Meny instead of many

Hotil instead of hotel

Vesitid instead of visited (Paper 36)

The second most frequent error as can be seen in the figure is capitalization. In the corpus, the total frequency of wrong use of capital letters was 252 times. In this study, we consider two instances of capitalization. Firstly, a writer is supposed to start a new sentence or paragraph with a capital letter. Secondly, a writer is supposed to write a capital letter in a first letter relating to special names such as proper nouns etc. In our analysis, we find in many instances, students used capital letters which were not supposed to be used because it was not the beginning of a sentence 
neither proper noun. On the other hand, there were many instances that the students were supposed to use capital letters but they failed to write it. For examples:

There are some Advantage and disadvantage (paper 39)

Some think Businesses that buy and sell securities (paper 7)

This Topic is Tooking about The advantages (paper 14)

the investing money in a hotel business (paper 1)

on the other hand, hotel business in salalah has some advantages. (paper 3)

The above examples in the corpus show clearly that in some instances students used capital letters which they were not supposed to use. In another instance, they were supposed to use capital letters but none of them used it.

Error in subject verb agreement was also prevalent in the corpus. This kind of error had a total occurrence of 107 times, indicating that it was the third most frequent error in the corpus. In fact, only 4 out of 40 essays did not have any instances of subject verb agreement error. In other words, 36 essays had this type of error with varying degree of frequencies. Some examples in the corpus are:

The holidays are necessary for everybody (paper 1)

Any investment has advantages (paper 18)

It has a good weather (paper 14)

Another aspect that students tend to make error was article. The figure 5 shows that the error occurred 69 times in the corpus. This happened in instances where the students were supposed to use article but they failed to use it. On the other hand, there were instances in which they used articles where they were not supposed to use it.

\subsection{Exploring the Context of Writing}

As mentioned in the methodology section, we adopted a textography approach to study writing practices. We will now present the results of exploring context of writing which may shed more insight on what might constrain or influence the way the writers write. We will first present the results of the questionnaire administered to participants. However, only twenty-one participants filled in the questionnaire.

One of the questions was asked to the students "how many essay writing sessions they had on the course?" The result of the question is shown in the below figure 6 .

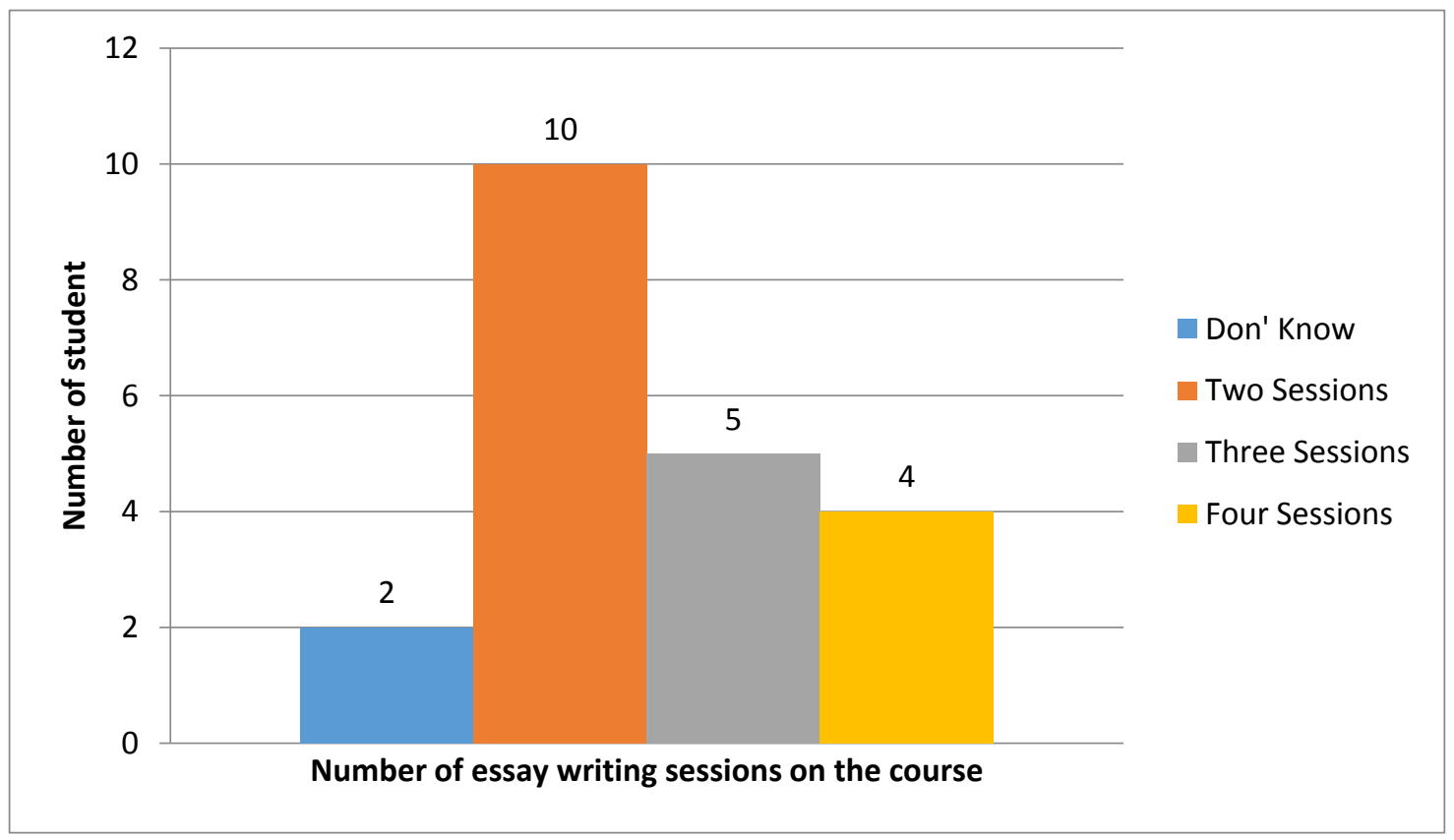

Figure 6. Number of essay writing sessions on the course 
The result in Figure 6 shows that 10 out of 21 respondents stated that they had only two sessions of teaching essay writing on the course over the semester. This figure represents almost 50 per cent of the total respondents. The figure also indicates that five respondents had three sessions and four respondents had four sessions. Two out of the total respondents did not know how many sessions they had on the course. Overall, the results clearly show that there is a lack of sufficient sessions for teaching essay writings. This result corroborates course syllable schedules, which we will discuss in details in discussion section.

Table 1. Some responses from the students' questionnaire

\begin{tabular}{ccccc}
\hline Element & $\begin{array}{c}\text { No. of } \\
\text { Respondent }\end{array}$ & Understand & Do not understand & Total \\
\hline Introductory paragraph & 21 & 20 & 1 & 21 \\
Thesis statement & 21 & 1 & 20 & 21 \\
Paragraph (parts) & 21 & 17 & 4 & 21 \\
Conclusion & 21 & 16 & 5 & 21 \\
Coherence & 21 & 5 & 16 & 21 \\
Linking words & 21 & 19 & 2 & 21
\end{tabular}

The result in Table 1 was a response regarding rhetorical structures of essay writing. The questions were related to whether students understand or do not understand the rhetorical structures of essay writing (see appendix I). Specifically, students were asked about the rhetorical structure of an introductory paragraph of an essay. As can be seen in the table almost all students did not know what thesis statement was. Because 20 out of 21 students showed ignorance or a lack of understanding of what thesis statement was and in which section of an essay a thesis statement is usually written. Another element where students were experiencing difficulty is coherence because 16 out of 21 students did not know what coherence was and how could their essay be coherent.

\subsubsection{A Lack of Critical Thinking}

Regarding the open-ended questions, the responses show that there is a lack of critical thinking to most of the respondents. For example, some of them say:

Lack of sources and information (Respondent 2)

We cannot gather the information (Respondent 3)

How to organize the essay and the order of ideas (Respondent 8)

Information about topic is very difficult (Respondent 11)

Not have enough information about the topic (Respondent 20)

This indicates that the students had difficulty in doing critical thinking. Because we mentioned in the context of the study above, the topics chosen were related to their majors and did not require specialized vocabulary. The students had to engage in critical thinking on the basis of their daily life experiences to come up with the advantages and disadvantages of either spending their holiday outside their country home or investing money in a hotel business in Salalah.

Furthermore, the teachers' responses corroborate this assertion. For instance, one of the teachers said that 'Information and ideas not presented in order and unable to combine ideas (Teacher 1). Another teacher had a similar perspective: 'students find it difficult to organize their ideas' (Teacher 3).

\subsubsection{Limited Range of Vocabulary}

The responses also indicated that almost all the respondents did not have a wide range of vocabulary. They were struggling with a very limited number of words which were difficult for them to use in their essays. For example, the respondents say:

We don't have many words (Respondent 1)

Arrange ideas and not bring the appropriate words (Respondent 5)

Sometimes I forget some important words (Respondent 6) 
This clearly shows that some of the students had difficulties in using a wide range of vocabulary, as well as appropriate words. These responses were similar to what teachers narrated because the teachers also shared similar concerns that students did not have a wide range of vocabulary. Some of the teachers' responses are:

They have very poor vocabulary (Teacher 1)

They are having limited vocabulary (Teacher 2 )

They don't use a wide range of words (Teacher 3)

This has a negative effect in their writing as the textual analysis shown.

\subsubsection{Spelling Errors}

The results of the corpus-based analysis show that spelling is the most frequent error. We explored the context of writing to get more insight why the error is recurring. The responses corroborate the results of the textual analysis because almost all the respondents stated that they were finding it difficult to spell most of the words correctly. Some of the respondents say:

Spelling of some words (Respondent 20)

English is not our first language difficult to write words (Respondent 21)

Furthermore, the responses of the teachers also indicate that the students find it challenging to spell many words correctly. This recurring of error might be associated with the fact that English language is a foreign language in Oman. The language of instruction in Circle 1 (Grade 1-4), Circle 2 (Grade 5-10) and Post-Basic Education (Grade 11-12) is Arabic language. The students are not exposed to English language only in High Schools. This factor might be one of the possible reasons for frequent spelling errors.

\subsubsection{Insufficient Essay Writing Sessions}

The course syllabus shows that sessions allocated to teaching essay writing were three hours for the whole semester (Spring). In our view, the three-hour session is not enough to adequately teach essay writing considering different rhetorical structures of essay writing such as introductory paragraph, including thesis statement; body paragraphs; concluding paragraphs; use of cohesive devices, generating ideas and choice of appropriate vocabulary.

The results of the questionnaires of both the faculty members and the students corroborate this claim because all the faculty members stated that the sessions were not enough to teach essay writing considering the levels of the students. As shown in figure 6 above that 15 out of 21 students stated that they had two or three sessions of teaching essay writing on the course.

\section{Discussion}

As mentioned above, this study triangulated the results of the textual analysis by exploring the context within which students are writing. The finding of this study in relation to spelling errors, which is the most frequent error in the corpus corroborate with findings of Al-Khasawneh, \& Maher, (2010), who find that students frequently make spelling errors in their essay. It also corroborates Al-Khairy's (2013) results which also indicate that students keep on making a lot of spelling errors. Regarding the construction of thesis statement, our findings show that only 15 out of 40 students wrote a thesis statement in their essay, suggesting that they had difficulty in writing up or they did not know what thesis statement is, as evidenced from their responses in the open-ended questionnaire. This finding is in consistence with the finding of Ahmed (2010), who finds that students had problems in writing up thesis statement. Furthermore, our results also indicate that only 15 out of 40 students write four topic sentences in each of the four paragraphs in the essay. Moreover, this finding reflects a similar result with findings of Ahmed (2010) that students had problems in writing up a topic sentence in each paragraph.

In addition, this study finds that students had difficulty in relation to coherence and use of appropriate cohesive devices. This is also reflected in their responses to the questionnaire. Our findings corroborate Al Badi'as (2015) finding that students faced difficulties in providing a coherent essay, including the use of appropriate cohesive devices. Our finding also suggests that students had problems with grammar, as well as using appropriate lexical items. These problems were also reflected in the students' responses to the open ended questionnaire. This finding is also corroborated with findings of Freed, et al. (2016) and Alfaqiri (2018) who both find that students had difficulties in grammar and use of appropriate vocabulary. The results of our study also suggest that students did not have a critical thinking, because their responses show that they did not know how to generate and organize ideas. This corroborates Javid and Umer's (2014) finding that students did not generate and organize appropriate ideas in their essays. This calls for more focus on writing in terms of time and practice allocated during teaching sessions. The 
Dhofar University students, as ESL/EFL learners study English in a setting where other languages are used on a daily basis and where reading English materials on a daily basis outside the classroom for students is still developing habit. This may partially explain the high rate and the variance of errors or mistakes that are found in their writing.

\section{Conclusion}

This study investigated students' writing difficulties and identified some of the most recurring errors in their essays. We also identified some of the possible factors that might cause the frequent errors. Some of the recurring errors were spelling, subject-verb agreement, and capitalization, a lack of coherence and cohesive devices. Other difficulties include absence of thesis statement and topic sentences in their essays. The exploration of the context of writing shows that the students did not have a critical thinking. They are found to master a limited range of vocabulary and insufficient essay writing contact hours. These factors could be some of the possible reasons that might influence some of the recurring errors.

\section{Teaching Implications}

There are a number of possible ways that teachers could assist students to improve their essay writing. The contextual data showed that they had very limited contact hours of teaching essay writing. Considering different elements and rhetorical structures of essay writing, we strongly recommend more contact hours for teaching essay writing. Alternatively, a new course, which will specifically focus on writing, could also be incorporated on the programme. Secondly, students would be encouraged to do more writing tasks during contact hours in the classrooms, including peer-review of their writing tasks. Thirdly, students should be encouraged to be acquiring a wide range of vocabulary through contact hours and outside the classroom. This could help them in addressing a problem of limited range of vocabulary. Fourthly, teachers could engage students in critical thinking activities, including generating and organizing ideas.

\section{Limitation of the Study}

One of the limitations of this study is that the number of the participants was forty. Therefore, the findings of the study cannot be generalized. However, our study emphasizes the notion of 'particularization' where findings cannot be generalized but focuses on particular individuals. It also provides more insight on students' writing difficulties. We recommend a further study which will involve a significant number of students from across disciplines and levels.

\section{Further Research}

We recommend a further study which would involve a large number of students' essays, as well as exploring the contexts of writing in details, involving many participants, both the faculty members and students. This might provide more insight of the students' writing practices.

\section{References}

Ahmed, A. H. (2010). Students' problems with cohesion and coherence in EFL essay writing in Egypt: Different perspectives. Literacy Information and Computer Education Journal (LICEJ), 1(4), 211-221. https://doi.org/10.20533/licej.2040.2589.2010.0030

Alsamadani, H. A. (2010). The relationship between Saudi EFL students' writing competence, L1 writing proficiency, and self-regulation. European Journal of Social Sciences, 16(1), 53-63.

Al Badi, I. A. H. (2015). Academic writing difficulties of ESL learners. In The 2015 WEI International Academic Conference Proceedings, $\quad l(1), \quad 65-78$. https://scholar.google.com/scholar?cites=12343659554527690183\&as_sdt=2005\&sciodt=0,5\&hl=en

Al Fadda, H. (2012). Difficulties in Academic Writing: From the Perspective of King Saud University Postgraduate Students. English Language Teaching, 5(3), 123-130. https://doi.org/10.5539/elt.v5n3p123

Alfaqiri, M. (2018). English Second Language Writing Difficulties and Challenges Among Saudi Arabian Language Learners. Journal for the Study of English Linguistics, 6(1), 24-36. https://doi.org/10.5296/jsel.v6i1.12740

Al-Khairy, M. A. (2013). Saudi English-Major Undergraduates' Academic Writing Problems: A Taif University Perspective. English Language Teaching, 6(6), 1-12. https://doi.org/10.5539/elt.v6n6p1

Al-Khasawneh, F. M. S., \& Maher, S. (2010). Writing for academic purposes: Problems faced by Arab postgraduate students of the college of business, UUM. ESP World, 9(2), 1-23.

Dornyei, Z. (2007). Research Methods in Applied Linguistics. Oxford University Press 
Fareed, M., Ashraf, A., \& Bilal, M. (2016). ESL learners' writing skills: Problems, factors and suggestions. Journal of Education and Social Sciences, 4(2), 81-92. https://doi.org/10.20547/jess0421604201

Grami, G. M. A. (2010). The effects of integrating peer feedback into university-level ESL writing curriculum: A comparative study in a Saudi context (Doctoral dissertation, Newcastle University).

Javid, C. Z., Farooq, U., \& Gulzar, M. A. (2012). Saudi English-major undergraduates and English Teachers' perceptions regarding effective ELT in the KSA: A Comparative Study. European Journal of Scientific Research, 85(1), 55-70.

Javid, C. Z., \& Umer, M. (2014). Saudi EFL learners' writing problems: a move towards solution. Proceeding of the Global Summit on Education GSE, 4-5.

Nunan, D. (1989). Designing tasks for the communicative classroom. Cambridge University Press.

Swales, J. M. (2013). Other floors, other voices: A textography of a small university building. Routledge. https://doi.org/10.4324/9780203811153

\section{Appendices}

\section{APPENDIX I}

\section{QUESTIONNAIRE FOR STUDENTS}

This questionnaire is part of a study that aims at exploring the essay writing practices of students of English for Business classes. Thank you for your time and cooperation.

1) How often do you practice essay writing in the class?

\begin{tabular}{|c|c|c|c|c|c|c|}
\hline Once per month & $\begin{array}{l}\text { Twice } \\
\text { month }\end{array}$ & per & Once a week & Twice per week & $\begin{array}{l}\text { Three times per } \\
\text { week }\end{array}$ & $\begin{array}{l}\text { More than three } \\
\text { times per week }\end{array}$ \\
\hline
\end{tabular}

2) How often do you practice essay writing outside the class?

\begin{tabular}{|c|c|c|c|c|c|c|}
\hline Once per month & $\begin{array}{l}\text { Twice } \\
\text { month }\end{array}$ & per & Once a week & Twice per week & $\begin{array}{l}\text { Three times per } \\
\text { week }\end{array}$ & $\begin{array}{l}\text { More than three } \\
\text { times per week }\end{array}$ \\
\hline
\end{tabular}

3) What are the parts of the Introduction in an essay?

4) What are the parts of a Paragraph in an essay?

5) What are the parts of a Conclusion in an essay?

6) What are the major difficulties that you face in essay writing?

7) In which courses did you practice essay writing before? 
8) What are the words that you use to link between ideas and parts in your writing? (eg. and, however)  9) For how many sessions have you studied and practiced essay writing in ENGL 203B course?

10) What is coherence in essay writing?

11) How can you create coherence in your essay writing?

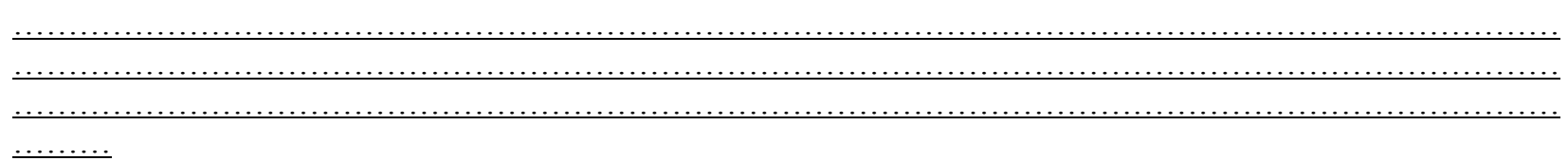
12) Do you have any suggestions to help students write better essays?

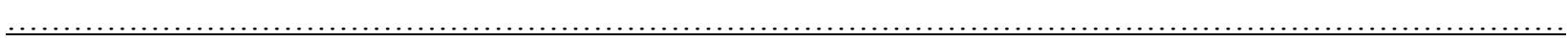

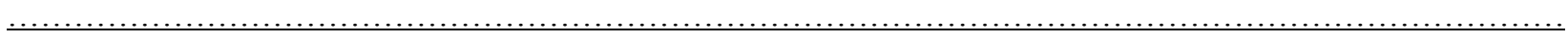

\section{APPENDIX II \\ QUESTIONNAIRE FOR TEACHERS}

This questionnaire is part of a study that aims at exploring the essay writing practices of students of English for Business classes. Thank you for your time and cooperation.

1) For how long have you been teaching this course?

2) Do you think that the course syllabus allocates enough sessions for teaching essay writing?

3) How often do you practice essay writing with your students in class per semester?

4) What are the difficulties that your students encounter in essay writing?

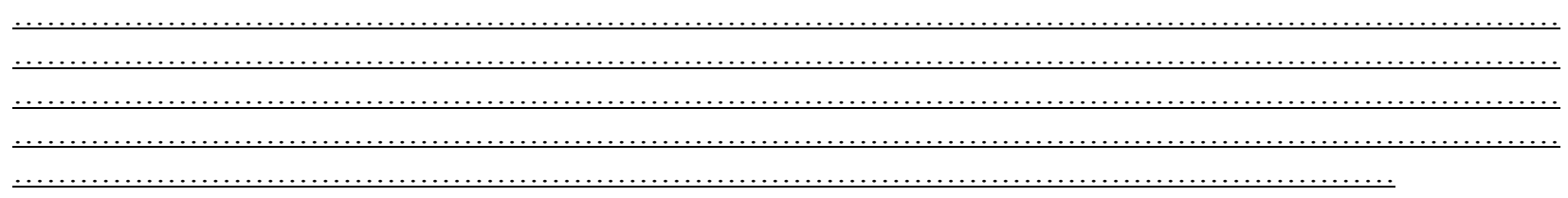

5) Do you think that students are able to produce a thesis statement in this course?

6) Do you think that students are able to use cohesive devices in this course?

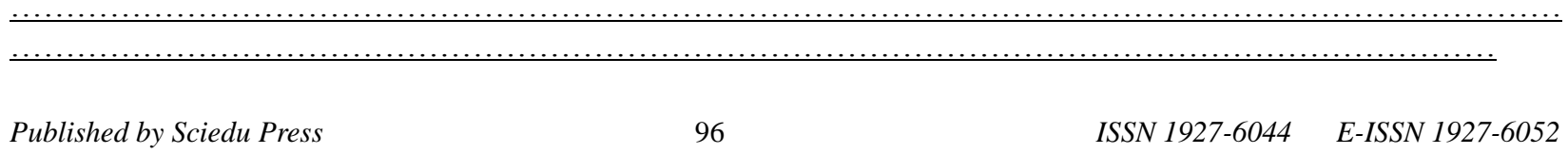


7) What are the most frequent cohesive devices that they tend to use in their essay writing?

 8) Do you think that they can use enough cohesive devices in their essay writing?



9) Do you think that students understand what is meant by coherence?

.

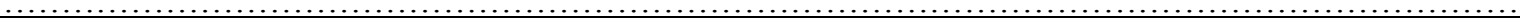

10) Do you think that students can create coherence in their essays?





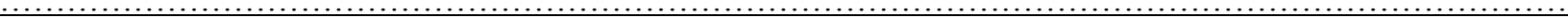

11) Do you have any recommendations to improve the essay writing skills of your students?

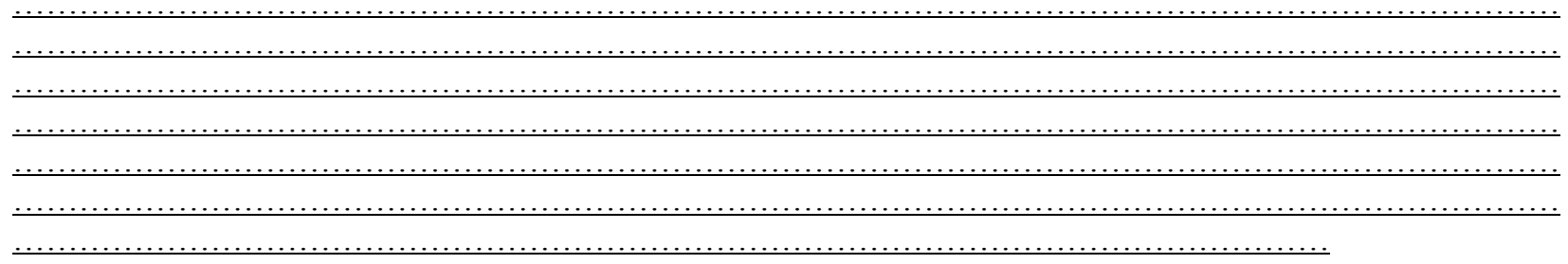

